\title{
Estudo do Processo de Operação de Reciclagem de Resíduos Provenientes da Coleta Seletiva de Lixo no Município de Itu/SP
}

\section{A Study of Recycling Operation Process from the Waste Selective Collection of Itu/SP City}

\author{
Recebido: 15/04/2015 - Aprovado: 22/05/2015 - Publicado: 27/06/2015
} Processo de Avaliação: Double Blind Review

\author{
Délvio Venanzi ${ }^{1}$ \\ Mestre em Engenharia de Produção/Administração \\ Coordenador e Professor do Curso de Engenharia de Produção \\ Universidade de Sorocaba \\ delvio.venanzi@prof.uniso.br \\ Henry Lesjak Martos \\ Pós-Doutorado - UAH - Universidade de Alacalá de Henares, Espanha. \\ Doutor em Engenharia Ambiental \\ Universidade de Sorocaba \\ henry.martos@gmail.com \\ Orlando Roque da Silva \\ Doutor em Engenharia de Produção \\ Coordenador e Professor do Mestrado em Engenharia de Produção \\ Centro Universitário das Faculdades Metropolitanas Unidas \\ orlando.roque@fmu.br
}

\begin{abstract}
Resumo: O presente trabalho é resultado de pesquisas realizadas na área de triagem de resíduos sólidos na COMAREI - Cooperativa de Materiais Recicláveis de Itu. Devido ao consumo desenfreado e o aumento do lixo doméstico, cooperativas vêm a necessidade de aprimoramento nos processos de separação e destinação desses resíduos. Novas técnicas ajudam a processar mais materiais e a acelerar o processo de coleta e a destinação de uma quantidade maior de materiais. O objetivo do trabalho é fazer o estudo de caso do funcionamento geral e do sistema de triagem da Cooperativa. A metodologia utilizada foi a realização de visitas com acompanhamento do fluxo de trabalho dos funcionários, observação de procedimentos e conversas espontâneas com os cooperados, além de pesquisa bibliográfica e levantamento de dados secundários. Como resultado se pode observar que os cooperados encontram dificuldade na triagem, pois a população não descarta o material corretamente; impedindo um melhor resultado e aproveitamento do tempo no processo de triagem. A operação do sistema semi mecanizado trabalha com a separação de sete tipologias de resíduos, sendo que dessas apenas cinco têm comercialização garantida.
\end{abstract}

\footnotetext{
${ }^{1}$ Autor para correspondência: Rodovia Raposo Tavares, Km 92,5 - Artura, Sorocaba - SP, Brasil - CEP: 18023-000.
} 
Palavras-Chaves: Resíduos sólidos. Reciclagem, Cooperativismo, Educação ambiental.

Abstract: This present work is the result of a survey in a solid waste sorting area COMAREI - Cooperative of Recyclable Materials in the city of Itu. Due to the unbridled consumption and increase in the amount of household waste, cooperatives have the need for improvement in their separation processes and disposal of such waste. New techniques allow to process more material and to accelerate the process of collecting and allocating a larger amount of material. The objective of this study was to analyse the overall functioning of the Cooperative screening system. The methodology was field research with visits to monitor the workflow of employees, their observation procedures and spontaneous conversations with members, as well as bibliographic research and collection of secondary data. As a result it can be observed that the cooperative members have difficulty in screening, because the population does not rule out the material properly; preventing a better use of time and result in the screening process. The operation of the semi-mechanized system works with the separation of seven types of waste, of which only five of these are guaranteed marketing.

Keywords: solid waste, recycling, Cooperative, environmental education.

\section{INTRODUÇÃO}

A carência de recursos naturais, associada aos problemas de acomodação de resíduos, levou o homem ao indispensável aprimoramento da reciclagem. Segundo o Ministério do Meio Ambiente “Cerca de 30\% de todo o 'lixo' é composto de materiais recicláveis com valor de mercado, pois são reaproveitados como matéria-prima no processo de fabricação de novos produtos". Seguindo esse pensamento, a COMAREI Cooperativa de Materiais Recicláveis de Itu - contribui com esse trabalho no município, sendo a total responsável pela coleta seletiva. Considerando o aumento do consumo não sustentável e o aumento do volume do lixo doméstico, esse estudo propõe a aplicação de novas técnicas que facilitem o processo de triagem e tragam resultados financeiros e sociais para a cooperativa.

No município de Itu, visando à minimização do problema do lixo, constituiu-se a COMAREI - Cooperativa de Materiais Recicláveis de Itu - que contribui com o trabalho de coleta, processamento e destinação, como sendo a responsável total pela coleta seletiva. 
Localizado a $101 \mathrm{~km}$ da capital paulista, o Estância Turística de Itu possui 160.608 habitantes, com uma densidade demográfica de 251,11 hab./km2 com um grau de urbanização de 93,59\% (SEADE, 2014). Ainda segundo a mesma fonte, as condições de vida no município mostram um Índice de Desenvolvimento Humano Municipal IDHM de 0,773. Quanto às condições ambientais de infraestrutura urbana, a Fundação SEADE (2014) informa que 93,64\% do município é atendido por coleta de lixo regular, $98,69 \%$ da população tem abastecimento de água e 96,62\% possui esgotamento sanitário.

Considerando o aumento do consumo não sustentável e o aumento do volume do lixo doméstico, a atividade de coleta de resíduos recicláveis torna-se imprescindível para a melhoria das condições ambientais urbanas, o que remete à importância das atividades da COMAREI.

O lixo produzido nas cidades está ficando cada dia mais problemático basicamente por dois motivos: o número de pessoas morando em zonas urbanas tornouse muito maior com uma geração de volumes de lixo cada vez maiores e a evolução de técnicas e de processos de desenvolvimento industrial produz cada vez mais tipos de lixo que a natureza não consegue destruir, como o caso dos não biodegradáveis.

Conceição e Medeiros (2009), em trabalho resultante de pesquisas sobre a formação das cooperativas, associam a reciclagem ao modelo capitalista vigente como instrumento econômico. Referem-se também a uma exploração globalizada onde se aceita a reciclagem como forma de suprir a falta de matéria-prima, pagando-se um preço bem inferior, se comparado à matéria-prima virgem, reduzindo os custos de produção. Concluem que o desenvolvimento sustentável "pró-capitalista", no qual a reciclagem em si não representa uma alternativa econômica e muito menos ambiental, somente ameniza momentaneamente as pressões sociais sobre o desemprego dos excluídos e proporciona um ganho para as indústrias, por meio da redução de seus custos, e estas, utilizando-se dos sucateiros, controlam o mercado de produtos reciclados.

É possível começar a enxergar as cooperativas com outros olhos. Durante o estudo, observou-se o difícil trabalho de um cooperado/catador e todos os obstáculos enfrentados. A reciclagem ainda representa um dos principais elementos no tratamento 
do lixo urbano, incluindo ganhos sociais com os trabalhadores, apesar de toda precariedade, informalidade e baixa remuneração evidenciando a dura inclusão.

Em outro estudo é comentado que:

Trata-se de uma inclusão perversa, pois como se pode verificar, com a lucratividade assegurada pelos processos de reciclagem, estes estão sendo realizados por pessoas de diferentes segmentos e até por organizações terceirizadas, o que conduz paulatinamente para nova exclusão dos catadores. (MEDEIROS e MACEDO, 2006).

A COMAREI conta com sua própria organização e gerenciamento, não sendo dependente de órgãos públicos, mas é vinculada à Prefeitura Municipal de Itu para algumas ações e/ou intervenções, como parcerias e doações. Com o aumento da oferta de materiais, o preço pago pelas indústrias compradoras irá cair, aumentando a condição de exploração dos catadores, onde em grande parte sustenta a viabilidade econômica da reciclagem (EIGENHEER, FERREIRA E ADLER, 2005). Mas, por outro olhar, estudos em várias cidades do Brasil têm mostrado que a renda dos catadores organizados em cooperativas, na maioria dos casos, supera o salário mínimo, sendo que esses catadores têm remuneração acima da média brasileira (D'ALMEIDA e VILHENA, 2000).

Carvalhal (2010) destaca que as cooperativas/associações são uma forma de diminuir a insegurança social em que se encontram os catadores, exercendo o seu trabalho nessas localidades sem serem explorados por atravessadores ou terceiros, podendo valorizar mais o seu trabalho com a atribuição de um valor mais significativo na venda do material reciclável. Na grande maioria dos trabalhos relacionados a este em questão, evidencia-se a precariedade do trabalho daqueles que lidam com a cata de material reciclável e a informalidade envolvida.

Considerando a dificuldade da sujeira, a população deve ser bem noticiada sobre a reciclagem para que possa se envolver nesses processos de maneira adequada. D'Almeida e Vilhena (2000) acreditam que o sucesso da coleta seletiva está intimamente associado aos investimentos feitos para sensibilizar e conscientizar a população. 
Os catadores que atuam em cooperativas têm se organizado cada vez mais, sendo que em 2000 foi criado o Movimento Nacional dos Catadores de Materiais Recicláveis, tendo como destaque a atividade de catação ser reconhecida pelo Ministério do Trabalho e incorporada ao Código Brasileiro de Ocupação (JACOBI, 2009).

Em seu trabalho sobre programas de coleta seletiva em parceria com associações de catadores, Besen (2006) complementa que as instabilidades dos programas de gestão sustentável relacionam-se ao baixo índice de coleta seletiva (relacionando com o potencial de material que poderia ser reciclado), ao alto índice de rejeito misturado ao material reciclável, à competição informal de catadores autônomos e à fragilidade dos convênios firmados com as prefeituras.

Também Troschinetz e Mihelci (2009) relacionam como sendo política governamental a caracterização dos resíduos produzidos, a separação dos materiais, a condição econômica dos munícipes, o gerenciamento de resíduos sólidos, a preparação técnica da equipe responsável, o plano de gestão, o mercado local para venda de materiais recicláveis, o grau de escolaridade dos munícipes, os recursos tecnológicos disponíveis, entre outros.

Nos últimos anos, trabalhos acadêmicos envolvendo reciclagem, reutilização e reuso de materiais e recursos energéticos estão sendo desenvolvidos, visando não somente ao gerenciamento e adequação das leis ambientais, mas também a ganhos do ponto de vista econômico, utilizando-se de novas tecnologias ou evidenciando a importância da logística reversa resultante da coleta seletiva (MATOS e SCHALCH, 2007).

Para Besen (2006) a coleta seletiva pode ser considerada como um dos componentes do gerenciamento integrado de RSU, definida como o recolhimento de materiais recicláveis, tais como papéis, plásticos, vidros, metais, previamente separados na fonte geradora e depois encaminhados à triagem e à venda desses materiais.

Apesar dos catadores realizarem um serviço importante, os trabalhadores sofrem preconceitos e são vistos como mendigos ou infratores pela sociedade. Também sofrem 
com a exploração dos atravessadores, que são grupos que se associam a catadores para cumprirem metas e atender à demanda de sucatas requisitadas pelas indústrias, porém estas pagam um preço muito abaixo daquele estipulado pelo mercado. Alguns estudos mostram que a criação de cooperativas evita e minimiza a ação dos atravessadores, além de garantir maior estabilidade e lucratividade e promover uma interdisciplinaridade no conceito da educação ambiental (RODRIGUES, 2005).

Portanto, a coleta seletiva é uma pauta importante para o desenvolvimento sustentável, porém, segundo Jacob e Besen (2011), apenas 8,2\% dos municípios brasileiros desenvolvem políticas de coleta seletiva e, consequentemente, apoio às cooperativas de catadores e recicladores de resíduos sólidos.

Porém as ações de coleta seletiva praticadas por todas as cooperativas existentes no país enfrentam problemas como a falta de conscientização da população para separação correta dos resíduos; sazonalidade do mercado em função da economia global no qual os preços dos resíduos variam de forma drástica; ausência de políticas públicas claras para o incentivo e apoio às cooperativas; falta de uma gestão eficaz e autônoma dentro das cooperativas e a precariedade das condições de trabalho e higiene na qual os catadores estão submetidos (RIBEIRO e BESEN, 2007).

O presente trabalho tem como objetivo principal fazer o estudo de caso do sistema de funcionamento operacional da COMAREI, com especial atenção às operações de triagem realizadas no fluxo produtivo. Como objetivos secundários devem ser mencionados a observação dos problemas relacionados à higiene e segurança do trabalho dos cooperados.

\section{METODOLOGIA DE PESQUISA}

O artigo classifica-se como uma pesquisa do tipo exploratória com a análise dos resultados de forma qualitativa e quantitativa pelo método da análise por conteúdo, uma vez que o trabalho foi desenvolvido in loco, ou seja, baseando-se em um estudo de caso com a finalidade de tornar a problemática explícita (GIL, 1996). Os dados obtidos foram extraídos da observação direta e acompanhamento semanal na Cooperativa, realizados entre agosto de 2013 e agosto de 2014. 
Dentro do estudo, também foram colhidos depoimentos por entrevistas informais com os cooperados e com os responsáveis pela cooperativa. Nestas visitas semanais foi observado o ambiente de trabalho, a sistemática de coleta, os procedimentos operacionais utilizados para a separação do material e a análise de documentações e planilhas de pagamento dos cooperados e balanço do inventário. Foram colhidos dados gerais da cooperativa, de como funciona a estrutura organizacional, sendo observada a entrada para descarga dos caminhões da coleta seletiva, os processos de triagem e de estocagem dos materiais a serem vendidos.

Durante as visitas à Cooperativa, alguns cooperados foram abordados para avaliação da evolução do empreendimento e para auxilio na visita. Medições do espaço físico do local foram realizadas antes e depois das alterações do espaço e tomadas notas dos métodos adotados na adaptação dos novos processos e técnicas de triagem. Foram colhidos dados do novo potencial com a esteira instalada e feita uma análise junto aos cooperados da evolução com as atuais técnicas. Realizou-se também um novo croqui do arranjo espacial com a disposição da esteira de triagem e do fluxo de produção, adequando o layout às necessidades dos cooperados.

\section{RESULTADOS E DISCUSSÃO}

A COMAREI tem papel de grande eficiência e produtividade na cidade de Itu. Atende à totalidade dos bairros e faz da cidade uma referência na questão da separação do lixo doméstico. Ao observar o modo de produção do local, conclui-se que, desde a união dos cooperados em dar início a uma cooperativa, o local já progrediu principalmente em gerenciamento e investimento no aprimoramento da rotina de triagem. O prédio atual da cooperativa conta com $3000 \mathrm{~m}^{2}$, onde cerca de $1350 \mathrm{~m}^{2}$ são de área coberta onde se localizam uma esteira de triagem, as máquinas de prensa e os materiais para venda.

A área é relativamente pequena para tamanha quantidade de lixo reciclável recebido diariamente, mas terá uma filial em outra área da cidade que ainda não conta com a coleta, onde serão atendidas mais 50 mil pessoas num espaço de $5800 \mathrm{~m}^{2}$ doados pela prefeitura. A esteira de triagem foi uma conquista da cooperativa no aperfeiçoamento da técnica de triagem, anteriormente manual. Trata-se de uma parceria 
entre a Prefeitura de Itu, a COMAREI e a ABIHPEC - Associação Brasileira da Indústria de Higiene Pessoal, Perfumaria e Cosmético - em uma logística reversa.

Os cooperados foram reeducados para o uso correto do sistema e dos Equipamentos de Proteção Individual - EPIs -, pois na atividade de separação, são usadas luvas, mas ainda não são usados o protetor auricular e a máscara - quanto aos decibéis, o protetor é importante, porque o ruído da esteira ao longo do tempo poderá causar problemas no corpo humano -, além das botinas, de acordo com a NR. 17 (Ergonomia). Precisam ser levadas em conta as pausas em função da repetitividade das operações (LER/DORT), os movimentos constantes e repetitivos com o braço e o giro do ombro na esteira. Ainda faltam também as botinas de segurança para evitar alguns acidentes com o pessoal de operação.

É possível começar a enxergar as cooperativas com outros olhos. Durante o estudo observou-se o difícil trabalho de um cooperado/catador e todos os obstáculos enfrentados. A reciclagem ainda representa um dos principais elementos no tratamento do lixo urbano, incluindo ganhos sociais com os trabalhadores, apesar de toda precariedade, informalidade e baixa remuneração, evidenciando a dura inclusão.

A produção se tornou mais eficaz com, em média, 40 toneladas/dia atualmente processadas, comparadas com 12 tonelada/dia anteriormente feitas, onde eram triados apenas $60 \%$ do material devido às condições menos eficazes. Anteriormente no método de separação havia pausas com mais frequência e os cooperados trabalhavam de forma não ergonômica, prejudicando a ação. Hoje, com a esteira, o processo é contínuo com até o dobro de eficiência, aumentando a produtividade, conforme a figura 1. 


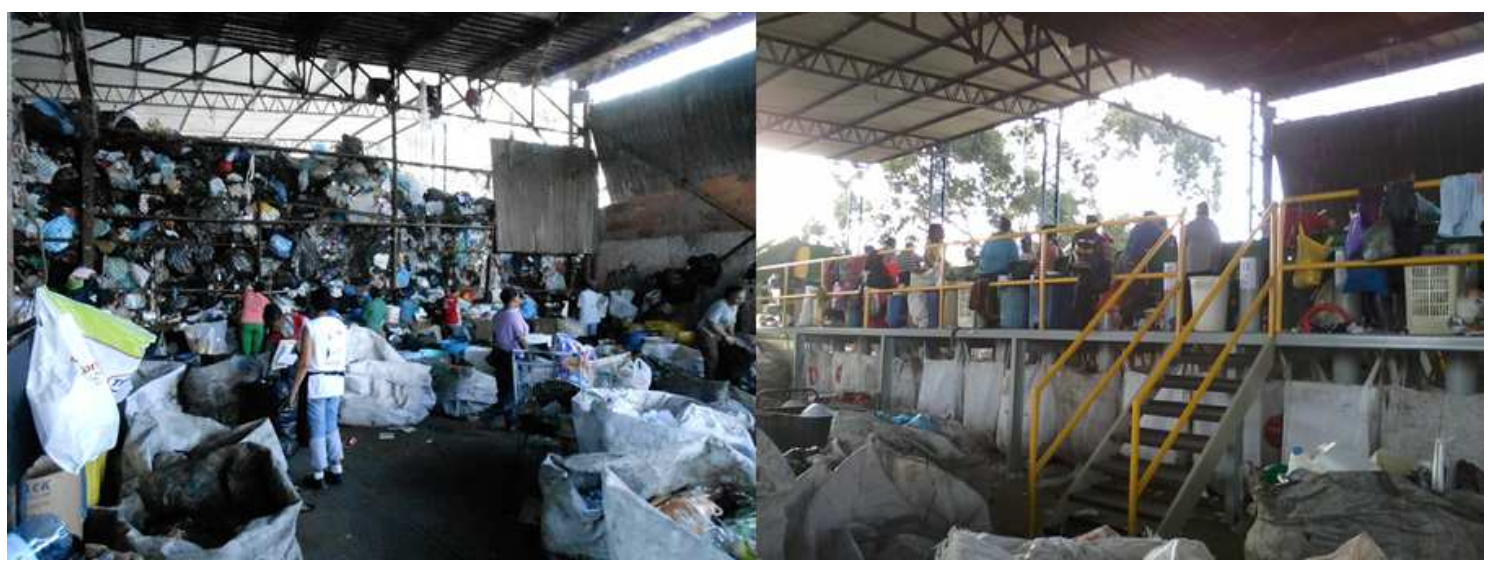

Figura 1: Fotos antes e depois - Implantação da esteira Fonte: Autores

Hoje a COMAREI é referência na região, realizando inclusive intercâmbios entre municípios para ciência e compreensão de uma cooperativa de reciclagem e seus benefícios. As figuras 2 e 3 mostram o aspecto geral do galpão e da operação da Cooperativa.

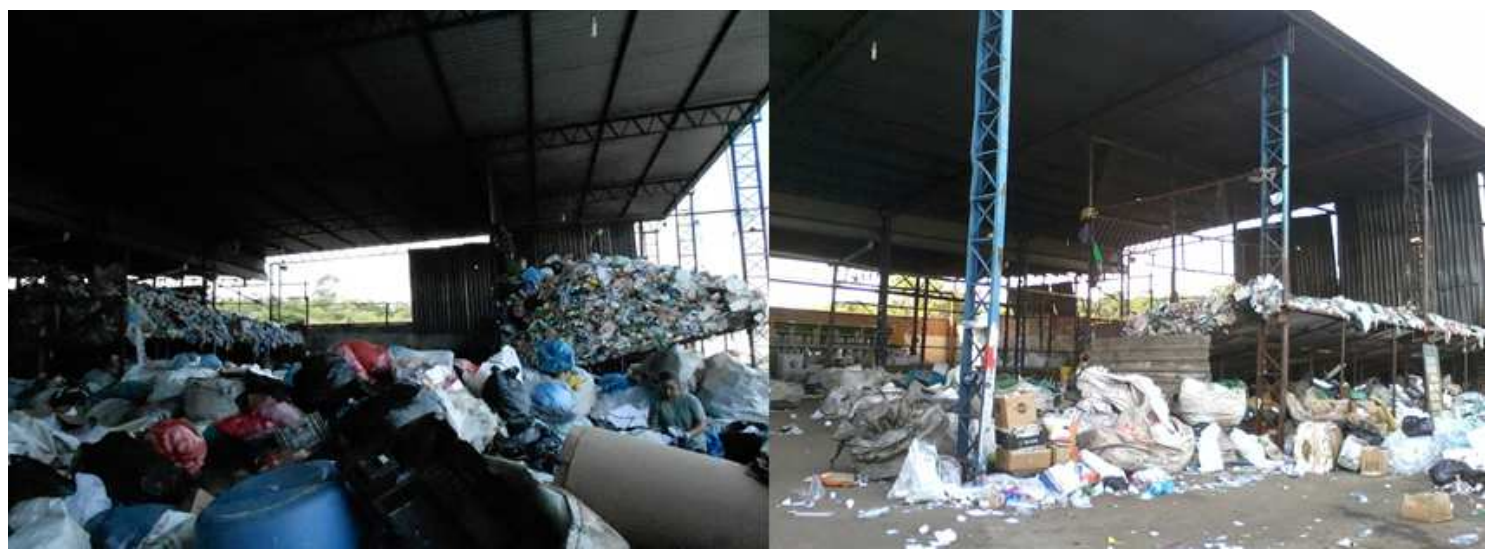

Figura 2 - Fotos da área de depósito

Fonte: Autores 


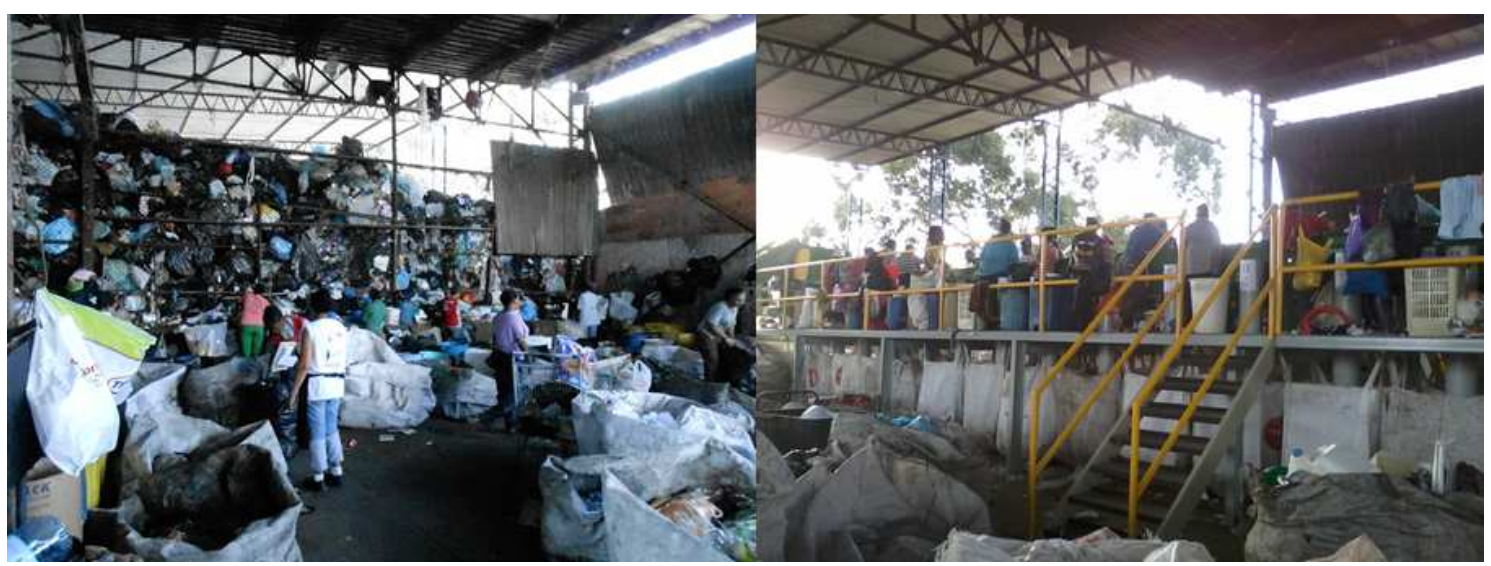

Figura 3 - Cooperados trabalhando na separação e triagem de material Fonte: Autores

De acordo com a Política Nacional de Resíduos Sólidos, os consumidores devem acondicionar e disponibilizar para coleta adequadamente e de forma diferenciada os resíduos sólidos gerados, sempre que estabelecido sistema de coleta seletiva pelo plano municipal de gestão integrada de resíduos.

Como contribuição, foi observada a real necessidade da separação prévia do lixo reciclável em tipos conforme a matéria base, como: plástico, papel, metal, vidro, não reciclável e orgânico, nas lixeiras coloridas. O caso seria viável se a população contasse com total conhecimento e informação de coleta seletiva e reciclagem, pois no descarte seletivo ocorrem equívocos e incertezas.

De fato a situação ideal se vincula à pré-separação dos materiais, poupando a triagem novamente dentro das cooperativas, que gera perda tempo e dinheiro. Analisando a situação, considerando a dificuldade da conscientização, sugere-se a utilização apenas dos seguintes descartes: resíduos recicláveis, resíduos não recicláveis e resíduos orgânicos. Onde as destinações seriam:

- Resíduos Recicláveis: as Cooperativas exerceriam a triagem e processamento dos materiais; 
- Resíduos Não Recicláveis e Orgânicos: direcionados pelo órgão público para aterros sanitários, ou no caso de resíduos orgânicos, destinados para a produção de adubos em composteiras.

Na separação foi recomendado utilizar a técnica do Husekeeping (5S`s), Seiri, Seiton, Seiso, Seiketsu, Shitsuke, com intuito de proporcionar aos trabalhadores uma organização mais adequada no ambiente de trabalho, proporcionando melhores resultados e um senso de organização do trabalho. Até o final da pesquisa a técnica estava no início, mas com muita motivação por parte dos trabalhadores.

Uma das principais dificuldades observadas neste estudo de caso foi a falta de conscientização da população no descarte dos resíduos. Vieira e Ricci (2010) consideram que as práticas de educação ambiental pela população, quase que em geral, vêm ocupando espaço dentro das comunidades, sendo considerado um importante instrumento, não só de formação de consciência, como também de apoio ao manejo de resíduos sólidos domiciliares urbanos, melhorando de forma direta a qualidade de vida dos catadores e indiretamente da população em geral.

Acrescentando, Ribeiro e Basen (2007) destacam que no Brasil não existe a responsabilização pós-consumo do setor produtivo, que na maioria dos municípios não há cobrança de taxas ou tarifas que promovam a sustentabilidade aos serviços de coleta e destinação de resíduos sólidos domiciliares, além de não existirem políticas públicas no âmbito municipal, estadual e nacional que incentivem as atividades de coleta seletiva e de reciclagem.

Nas entrevistas com os cooperados e analisando o trabalho por eles realizado, é de se salientar a falta de segurança e higiene dos trabalhadores. Muitos não utilizavam os EPIs - Equipamentos de Proteção Individual, que eram doados por empresas como a do Grupo Coca-Cola. Rodrigues (2011) ressalta que o sistema voltado à coleta seletiva não consegue atender à demanda do país. As cooperativas devem ser rigorosamente fiscalizadas para que os trabalhadores tenham condições de trabalhar e ter o resultado positivo de sua atividade. Agrega-se a isso, principalmente, o baixo nível social e cultural da maioria dos cooperados/catadores. 


\section{CONCLUSÕES}

Em vista, no inicio, às necessidades da Cooperativa, vê-se hoje que já contam com mais tecnologia e condições para crescimento e autodesenvolvimento. Ainda encontram dificuldades, principalmente, em relação ao descuido da população com o material destinado à coleta seletiva. A educação ambiental é escassa, levando prejuízos à cooperativa, devido ao resíduo orgânico presente nos materiais que irão ser reciclados. O resíduo orgânico presente no material reciclável e não reciclável que a COMAREI recebe gera mau cheiro, atrai animais e, mais especialmente, dobra o trabalho na hora da triagem pela necessidade de se realizar uma triagem mais minuciosa, necessitando de EPIs.

A dificuldade seria resolvida de forma muito simples se, primeiramente, a população geradora frequentasse cooperativas de reciclagem para noção de onde se destina seu lixo e também se houvesse um maior enfoque dos órgãos responsáveis em educação ambiental para a população se integrar no assunto. Sugere-se para o descarte seletivo uma nova perspectiva sobre o ponto de vista da cooperativa. Devido à dificuldade de atingir o ideal na conscientização dos resíduos que são descartados nas lixeiras seletivas coloridas, a proposta vem da união dos materiais recicláveis em um só descarte, separados dos materiais não recicláveis e dos orgânicos, sobre o ponto de vista da retriagem que é feita nas cooperativas, facilitando o trabalho de educação ambiental visando à praticidade.

Outra dificuldade clara da COMAREI é o limite físico de espaço, dificultando o trabalho realizado pelos cooperados. Sendo assim, a cooperativa vê a necessidade de ampliação com uma filial do outro lado do município, cuja região contará com o serviço de coleta seletiva.

\section{REFERÊNCIAS}

BESEN, G. R. Programas municipais de coleta seletiva em parceria com organizações de catadores na Região Metropolitana de São Paulo: desafios e perspectivas. Dissertação de Mestrado. Universidade de São Paulo. 195p. 2006. 
BESEN, G. R; GUNTHER,W.M.R; RODRIGUEZ, A.C.;BRASIL,A.L. Resíduos sólidos: vulnerabilidades e perspectivas. In: SALDIVA P. et al. Meio Ambiente e Saúde: o desafio das metrópoles. São Paulo, Ex Libris, 2007.

CARVALHAL, M.D. A precaridade do trabalho dos catadores de material reciclável no oeste paranaense e a dinâmica estratégica da reprodutividade do capital. Revista Pegada Eletrônica, Presidente Prudente, vol.11, n. 2, 31 de dezembro 2010. Disponível em: 〈http://www.fct.unesp.br/cegt/pegada >. Acesso em fevereiro de 2015.

CONCEIÇÃO, M.M.; MEDEIROS, O.R. A Reciclagem dos Resíduos Sólidos Urbanos e o Uso das Cooperativas de Reciclagem - Uma Alternativa aos Problemas do Meio Ambiente. Revista Enciclopédia Biosfera. Goiânia. 5(8):1-16. 2009

D'AlMEIDA, M. L. O.; VILHENA, A. (Coord.). Lixo municipal: Manual de Gerenciamento Integrado. São Paulo: IPT/CEMPRE, 2000. 232p.

EIGENHEER, E. M.; FERREIRA, J. A.; ADLER, R. R. Reciclagem: mito e realidade. Rio Janeiro: Fólio, 2005. 197p.

GIL, Antônio. Carlos. Como Elaborar Projetos de Pesquisa. São Paulo: Atlas, 1996. $124 \mathrm{p}$.

JACOB, P.R., BESEN, G.R. Gestão de Resíduos Sólidos em São Paulo: Desafios de Sustentabilidade, Estudos Avançados, 25 (71), 2011, 135-158.

JACOBI, P. Gestão compartilhada dos resíduos sólidos no Brasil: inovação com inclusão social. São Paulo: Editora: Annablume. 2009. 138p.

MANCINI, S.D. et al. Oportunidades de Melhoria na Gestão de Resíduos em Empresas Distribuidoras de Eletricidade: o caso da AES Eletropaulo. Revista de P\&D Aneel. , v.4, p.101 - 103, 2011.

MATOS, T.F.L., SCHALCH, V., Composição dos Resíduos Poliméricos, Pós Consumo, Gerados no Município de São Carlos, Polímeros: Ciência e Tecnologia, vol. 17, no 4, p. 346-351, 2007.

MEDEIROS, L.F.R.; MACEDO, K.B. "Catador de Material Reciclável: Uma profissão para além da sobrevivência"? Psicologia \& Sociedade: 18(2): 62-71: mai/ago. 2006.

RODRIGUES, A. M. Produção e consumo do e no espaço: problemática ambiental urbana. São Paulo: Hucitec, 2005. 157p.

RODRIGUES, L.F.O. Saneamento e cooperativas de catadores de materiais recicláveis. Revista do Curso de Direito Uniabeu. V.1, n1, 31-46. 2011.

CARVALHAL, M. D, RIBEIRO, S. Q. ROSS, D. A precariedade do trabalho dos catadores de material reciclável no oeste paranaense e a dinâmica estratégica da reprodutividade do capital. Revista Pegada Eletrônica, Presidente Prudente, vol. 11, n. 2, $31 \quad$ dezembro 2010.2 Disponível em: 
<http://www.fct.unesp.br/ceget/pegada112/06ROSS1102.pdf>. Acesso em: março de 2014.

SANTIN, M.F.C.L., Proposta para o Desenvolvimento Sustentável Local que Privilegiam a Conservação Ambiental e a Inserção Social, Ensaios FEE, V.30, n.2, p. 777-798, 2009.

SANTOS, J.G. A importância das cooperativas de reciclagem na gestão dos resíduos sólidos urbanos: um estudo em uma cooperativa de Campina Grande-PB, In: XIV Seminário em Administração - SemeAd, São Paulo, SP, Anais... São Paulo SEMEAD, 2011.

SEADE, Fundação Sistema Estadual de Análise de Dados. Estância Turística de Itú. Disponível em <http://www.redebrasilatual.com.br/ambiente>. Acesso em março de 2014.

TROSCHINETZ, A. M.; MIHELCIC, J. R. Sustainable recycling of municipal solid waste in developing countries. Waste Management. n. 29, p. 915-923, 2009. 